\title{
Low mean perfusion pressure is a risk factor for progression of acute kidney injury in critically ill patients - A retrospective analysis
}

\author{
Marlies Ostermann ${ }^{1 *}$ (D) Anna Hall ${ }^{2}$ and Siobhan Crichton ${ }^{3}$
}

\begin{abstract}
Background: The aim was to investigate whether mean perfusion pressure (MPP) calculated as the difference between mean arterial pressure (MAP) and central venous pressure (CVP) was associated with risk of progression from AKI I to AKI III in critically ill patients.

Methods: Retrospective analysis of adult patients admitted to a multi-disciplinary adult intensive care unit (ICU) between July 2007 and June 2009 who developed AKI I and in whom advanced haemodynamic monitoring was initiated within $12 \mathrm{~h}$ of diagnosis of AKI I. We compared patients with a MPP above and below the median value in the first $12 \mathrm{~h}$ of diagnosis of AKI. Multivariable logistic regression analyses were performed to identify independent risk factors for progression to AKI III, to explore the impact of MAP and CVP separately, and to investigate the impact of MPP in pre-defined sub-groups.

Results: Among 2118 ICU patients, 790 patients (37\%) developed AKI I of whom 205 underwent advanced haemodynamic monitoring within $12 \mathrm{~h}$ of AKI stage I. Their median MPP was $59 \mathrm{mmHg}$. AKI I patients with a MPP $\leq 59 \mathrm{mmHg}$ had a significantly higher risk of progressing to AKI stage III (48.6\% versus 34\%, respectively; $p=0.0034)$. This association was stronger in patients with ischemic heart disease, congestive cardiac failure or without pre-existing hypertension and in patients with a MAP $<65 \mathrm{mmHg}$ for $>1 \mathrm{~h}$. As individual components, a raised CVP was independently associated with progression to AKI stage III but MAP alone was not an independent risk factor for AKI progression.
\end{abstract}

Conclusion: MPP $<60 \mathrm{mmHg}$ was independently associated with AKI progression. CVP was the key component of MPP.

Keywords: Acute kidney injury, Central venous pressure, Mean perfusion pressure, Haemodynamics, Risk of progression

\section{Background}

Acute kidney injury (AKI) is one of the most common complications of critical illness affecting 50-60\% of patients admitted to the Intensive Care Unit (ICU) $[1,2]$. It is associated with serious short- and long term complications, including increased mortality and contributes to significant healthcare costs [3-5]. Worldwide, opportunities are sought to prevent AKI and to reduce the risk of progression.

\footnotetext{
* Correspondence: Marlies.Ostermann@gstt.nhs.uk

'Department of Critical Care, King's College London, Guy's \& St Thomas' NHS

Foundation Trust, Westminster Bridge Road SE1 7 EH, London, UK

Full list of author information is available at the end of the article
}

Haemodynamic regulation of renal blood flow and renal venous pressure are key determinants of renal function. In healthy individuals without systemic hypertension, intrarenal blood flow is auto-regulated at renal perfusion pressures between 60 and $100 \mathrm{mmHg}$ [6]. During critical illness, these processes may be compromised. A raised central venous pressure (CVP) and the resultant increased backward pressure also negatively impacts on renal function, mainly due to renal congestion and increased intra-renal pressure resulting in a fall in glomerular filtration rate (GFR) [7-10]. Most evidence stems from studies in patients with cardiovascular disease where an association between renal venous 
congestion and the development of AKI has been repeatedly shown [11-16].

To date, there are no established techniques to evaluate and monitor intrarenal blood flow and renal perfusion pressures directly [17]. There are also no reliable means to predict intrarenal haemodynamics from systemic arterial pressures. It has been suggested that mean perfusion pressure (MPP) may serve as a surrogate. MPP is calculated as the difference between systemic mean arterial pressure (MAP) and CVP, ie MPP = MAP - CVP [18] Previous studies have shown that a lower MPP was associated with an increased risk of developing AKI [19]. It remains unknown whether MPP also affects the risk of progression in patients with established AKI.

\section{Methods}

\section{Aims}

The aims of this study were.

i) to explore whether patients with a new diagnosis of AKI stage I and a calculated MPP below the median value had a higher risk of progression to AKI stage III than AKI I patients with a MPP above the median;

ii) to investigate whether MAP or CVP as individual components of MPP have a greater impact on risk of progression from AKI stage I to AKI stage III.

\section{Setting}

Guy's \& St Thomas' NHS Foundation Hospital is a tertiary care centre with a 43-bed, level 3 multidisciplinary adult intensive care unit (ICU). The ICU has a fully computerised electronic patient record system where all data are recorded at the time of generation.

\section{Patient and study design}

In this ancillary investigation of a previously reported study [20,21], we retrospectively analysed a database of all patients admitted to the ICU between July 2007 and June 2009. Using the creatinine criteria of the AKI Network (AKIN) classification, we retrospectively identified patients with AKI stage 1 (AKI I) (i.e., rise in serum creatinine by $\geq 0.3 \mathrm{mg} / \mathrm{dl}[\geq 26.4 \mu \mathrm{mol} / \mathrm{L}]$ or by $\geq 50 \%$ from baseline in $\leq 48 \mathrm{~h}$ ) [22]. We only used serum creatinine results obtained during the relevant hospitalization to diagnose AKI in order to comply with the 48-h time window and considered the lowest creatinine result as the baseline value. We selected all patients in whom advanced haemodynamic monitoring had been initiated for clinical reasons within $12 \mathrm{~h}$ of the patient meeting the criteria for AKI I.

All patients had an internal jugular vein central venous catheter. Patients with a renal transplant, re-admissions, and patients who left the ICU within $24 \mathrm{~h}$ of diagnosis of AKI I or developed AKI stage III within $12 \mathrm{~h}$ of diagnosis of AKI I were excluded. The outcome of interest was progression to AKI stage III.

\section{Data collection}

As previously reported [20], we collected demographics, co-morbidities and Sequential Organ Failure Assessment (SOFA) score on admission to ICU and day of AKI I. We also recorded routine haemodynamic parameters obtained by advanced haemodynamic monitoring and arterial lactate concentration during the first $12 \mathrm{~h}$ period after diagnosis of AKI I. The MAP and CVP obtained during the first set of advanced haemodynamic monitoring were used to calculate the MPP. Indexed oxygen delivery $\left(\mathrm{DO}_{2} \mathrm{I}\right)$ was calculated as $\mathrm{DO}_{2} \mathrm{I}=1.34 \mathrm{X}$ haemoglobin concentration $\mathrm{X}$ oxygen saturation $\mathrm{X}$ cardiac index. Cumulative fluid balance was determined from all recorded fluid input and output data.

\section{Statistics}

MPP was calculated as the difference between MAP and CVP taken during the immediate $12-\mathrm{h}$ period after diagnosis of AKI I. Characteristics of patients were summarised as median (interquartile range), mean (standard deviation) or frequency (percentage) and compared between patients with a MPP above and below the median value using Mann Whitney, t-test or chi-square tests as appropriate.

The association between MPP and the odds of progressing to AKI III was explored by multivariable logistic regression analysis with adjustment for factors previously shown to be associated with risk of progression, ie. age, indexed oxygen delivery, arterial lactate concentration, cumulative fluid balance and SOFA score $[20,21]$. The odds ratios (OR) and respective 95\% confidence intervals $(\mathrm{CI})$ were calculated. To explore the possibility of a non-linear relationship between MPP and AKI progression, models were fitted allowing for a quadratic, then cubic relationship between MPP and odds of progression. A further model included MPP categorised into bands of width $10 \mathrm{mmHg}$. Models were also stratified by presence of pre-existing hypertension, ischaemic heart disease (IHD), congestive cardiac failure (CCF), CVP $>15 \mathrm{mmHg}$ or severe hypotension (ie. MAP $<65 \mathrm{mmHg}$ for $1 \mathrm{~h}$ or more).

The individual impact of CVP and MAP on the effect of MPP was explored using both parameters as continuous measures. The model was adjusted for relevant confounding factors.

Stata 13MP was used to conduct the analyses.

\section{Results}

Between July 2007 - June 2009, 2118 patients were admitted to the ICU of whom 790 patients (37\%) met the criteria for new onset of AKI I. Sixty-nine patients 
were excluded. (Fig. 1) Among the remaining 721 patients, haemodynamic monitoring using pulse induced contour or lithium dilution cardiac output technique was initiated by the clinical team in 210 patients within $12 \mathrm{~h}$ of AKI I. Five patients were excluded from this analysis as they died before AKI I resolved or progressed. The median age of the remaining 205 patients was 70 years, $67 \%$ were male and $44 \%$ had underlying IHD or CCF. (Table 1) The median MPP was $59 \mathrm{mmHg}$.

At baseline, there was a significantly larger proportion of patients admitted with acute neurological disorders among those with MPP $>59 \mathrm{mmHg}$. (Table 1) There was no other significant difference between patients with a MPP $\leq 59 \mathrm{mmHg}$ versus MPP $>59 \mathrm{mmHg}$ following AKI I.
On day of AKI I, patients with MPP $\leq 59 \mathrm{mmHg}$ had a significantly higher SOFA score $($ mean $=9.2$ versus $8.1 ; p=0.003$ ). (Table 1 ) Within the initial $12 \mathrm{~h}$ period after diagnosis of AKI I, patients with a MPP $\leq 59 \mathrm{mmHg}$ had a significantly higher CVP (median $=14$ versus 11, $p<0.001$ ) and required vasopressor support more often $(94.3 \%$ versus $83 \%$; $p=0.010)$. (Table 1 ).

\section{Progression to AKI III}

AKI I patients with a MPP $\leq 59 \mathrm{mmHg}$ during the initial $12 \mathrm{~h}$ after diagnosis of AKI I had a significantly higher risk of progression to AKI III compared to AKI I patients with MPP $>59 \mathrm{mmHg}(48.6 \%$ versus $34 \%$, respectively; $p=0.0034)$. Multivariable regression analysis confirmed that SOFA score on day of AKI I and

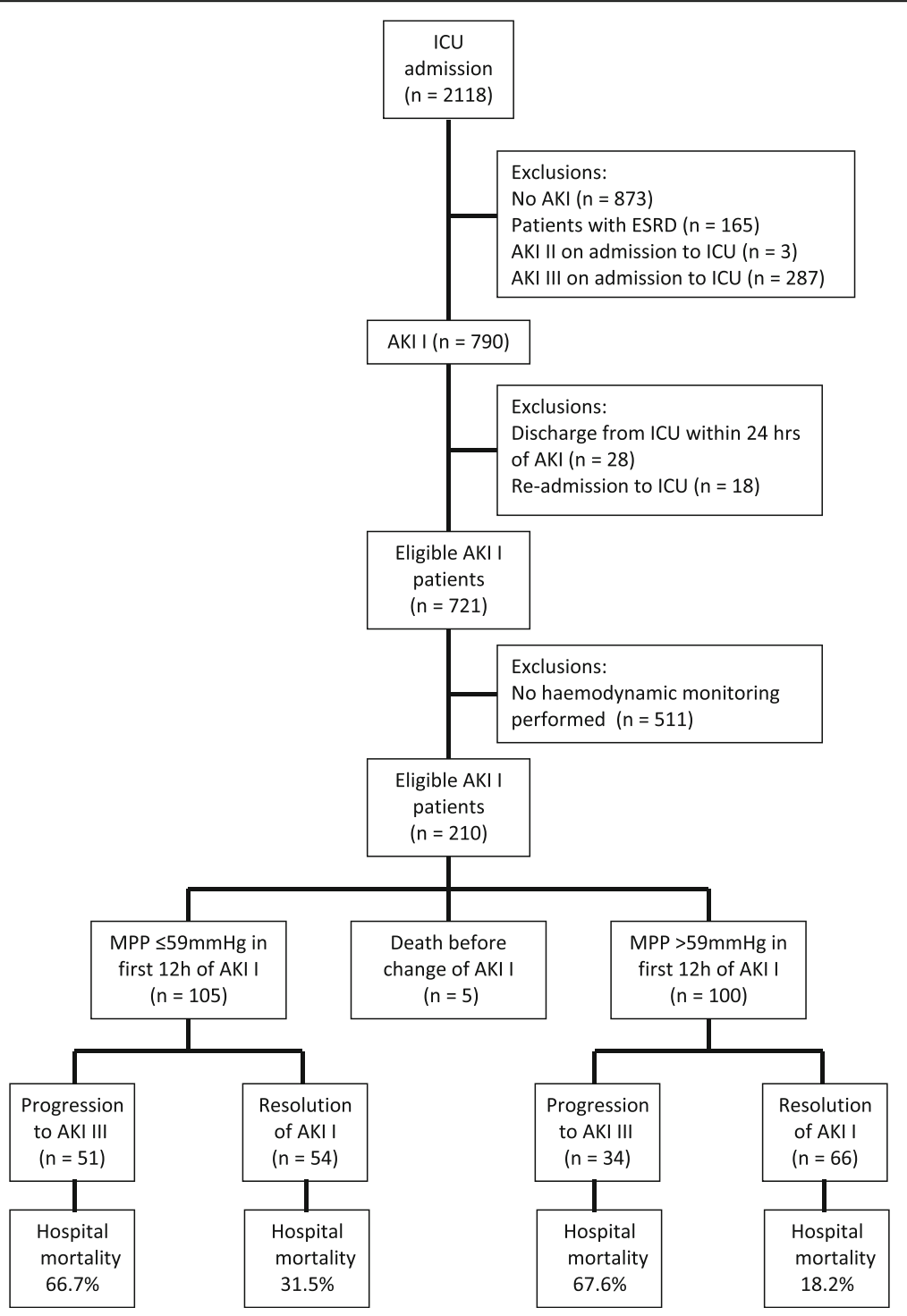

Fig. 1 Patient flow. Abbreviations: AKI = acute kidney injury; ESRD = end stage renal disease; ICU = intensive care unit; MPP = mean perfusion pressure 
Table 1 Patient characteristics

\begin{tabular}{|c|c|c|c|c|}
\hline & Total cohort $n=205$ & MPP $\leq 59 \mathrm{mmHg} n=105$ & MPP $>59 \mathrm{mmHg} n=100$ & $p$-value \\
\hline Age, median (IQR) & $70(56-77)$ & $71(56-78)$ & $70(57-78)$ & 0.66 \\
\hline Male gender, n (\%) & $138(67.3)$ & $72(68.6)$ & $66(66.0)$ & 0.70 \\
\hline \multicolumn{5}{|l|}{ Comorbidities } \\
\hline IHD / CHF, n (\%) & $90(43.9)$ & $45(42.9)$ & $45(45.0)$ & 0.76 \\
\hline Diabetes, n (\%) & $38(18.5)$ & $17(16.2)$ & $21(21.0)$ & 0.38 \\
\hline Hypertension, n (\%) & $79(38.5)$ & $35(33.3)$ & $44(44.0)$ & 0.12 \\
\hline CKD, n (\%) & $25(12.2)$ & $12(11.4)$ & $13(13.0)$ & 0.73 \\
\hline COPD, n (\%) & $26(12.7)$ & $11(10.5)$ & $15(15.0)$ & 0.33 \\
\hline CLD, n (\%) & $11(5.4)$ & $6(5.7)$ & $5(5.0)$ & 0.82 \\
\hline \multicolumn{5}{|l|}{ Admission diagnosis } \\
\hline Post-surgical, n (\%) & $72(35.1)$ & $34(23.3)$ & $38(38.0)$ & \multirow[t]{6}{*}{0.88} \\
\hline Cardiac emergency, n (\%) & $53(25.9)$ & $29(27.6)$ & $24(24.0)$ & \\
\hline Sepsis, n (\%) & $35(17.1)$ & $18(17.1)$ & $17(17.0)$ & \\
\hline Respiratory emergency, n (\%) & $34(16.6)$ & $17(16.2)$ & $17(17.0)$ & \\
\hline Gastrointestinal emergency, n (\%) & $7(3.4)$ & $5(4.8)$ & $2(2.0)$ & \\
\hline Other, n (\%) & $3(1.5)$ & $1(1.0)$ & $2(2.0)$ & \\
\hline \multicolumn{5}{|l|}{ Parameters on admission to ICU } \\
\hline SOFA score, mean (SD) & $7.1(2.8)$ & $7.5(2.6)$ & $6.8(2.9)$ & 0.09 \\
\hline APACHE II score, median (IQR) & $18(14-21)$ & $17(14-21)$ & $18(13-21)$ & 0.80 \\
\hline \multicolumn{5}{|l|}{ Parameters on day of AKI I } \\
\hline SOFA score, mean (SD) & $8.7(2.7)$ & $9.2(2.7)$ & $8.1(2.7)$ & 0.003 \\
\hline Cumulative fluid balance [ml], median (IQR) & $2363(52-3812)$ & $2149(802-3643)$ & $2568(994-4116)$ & 0.234 \\
\hline Sepsis, n (\%) & $122(59.8)$ & $57(54.8)$ & $65(65)$ & 0.138 \\
\hline \multicolumn{5}{|l|}{ Parameters within $12 \mathrm{~h}$ of diagnosis of AKI I } \\
\hline $\mathrm{DO}_{2} \mathrm{I}\left[\mathrm{ml} / \mathrm{min} / \mathrm{m}^{2}\right]$, median (IQR) & $362(277-4836)$ & $347(270-459)$ & $377(296-494)$ & 0.132 \\
\hline Arterial lactate $[\mathrm{mmol} / \mathrm{L}]$, median $(\mathrm{QQR})$ & $1.7(1.3-2.6)$ & $1.8(1.2-2.6)$ & $1.7(1.3-2.6)$ & 0.833 \\
\hline MAP <65 mmHg for $>1$ h, n (\%) & $107(52.2)$ & $74(70.5)$ & $33(33.0)$ & $<0.001$ \\
\hline MAP during $12 \mathrm{~h}$ [mmHg], median (IQR) & $73(69-78)$ & $69(66-73)$ & $78(73-83)$ & $<0.001$ \\
\hline CVP $[\mathrm{mmHg}]$, median (IQR) & $14(10-18)$ & $14(11-18)$ & $11(9-15)$ & $<0.001$ \\
\hline Vasopressor use, n (\%) & $182(88.8)$ & $99(94.3)$ & $83(83.0)$ & 0.01 \\
\hline
\end{tabular}

Abbreviations: APACHE Acute Physiology and Chronic Health Evaluation, AKI acute kidney injury, CCF congestive cardiac failure, CKD chronic kidney disease, COPD chronic obstructive pulmonary disease, CLD chronic liver disease, CVP central venous pressure, $D \mathrm{O}_{2} l$ oxygen delivery index, IHD ischaemic heart disease, $I Q R$ interquartile range, MAP mean arterial pressure, MPP mean perfusion pressure, SD standard deviation, SOFA sequential organ failure assessment

MPP, $\mathrm{DO}_{2} \mathrm{I}$ and first arterial lactate concentration within $12 \mathrm{~h}$ of diagnosis of AKI I were independently associated with AKI progression. (Table 2) For each one point increase in MPP, the odds of progression to AKI III decreased by $4.5 \%(\mathrm{OR}=0.96 ; 95 \%$ CI $0.92-0.996$; $p=0.031$ ). In sensitivity analyses there was no evidence of a non-linear relationship between MPP and odds of progression.

\section{Subgroup analysis}

It was hypothesised that the effect of MPP on risk of progression to AKI III may differ in high-risk patients, including those with cardiac disease, pre-existing hypertension, a CVP $>15 \mathrm{mmHg}$ or a MAP $<65 \mathrm{mmHg}$ for more than $1 \mathrm{~h}$ in the 12-h period following diagnosis of AKI I. Subgroup analyses confirmed that MPP was significantly associated with odds of progression to AKI III in patients with IHD or CCF, in patients with MAP $<65 \mathrm{mmHg}$ for $>1 \mathrm{~h}$ and also in patients without pre-existing hypertension. (Table 3 ) Tests of interaction between each of these variables and MPP were statistically non-significant $(p>0.1)$.

\section{Comparison of impact of CVP and MAP}

Multivariable analysis using CVP and MAP as individual components showed that CVP was an independent risk 
Table 2 Multivariable analysis: Risk factors for progression from AKI I to AKI III

\begin{tabular}{|c|c|c|}
\hline Parameter & OR $(95 \% C l)^{a}$ & $p$-value \\
\hline $\begin{array}{l}\text { First arterial lactate following } \\
\text { diagnosis of AKI I [mmol/L] }\end{array}$ & $1.45(1.12-1.89)$ & 0.005 \\
\hline SOFA score on day of AKI I & $1.20(1.05-1.37)$ & 0.01 \\
\hline $\begin{array}{l}\text { First } \mathrm{DO}_{2} \mathrm{l} \text { in } 12 \mathrm{~h} \text { period after } \\
\text { diagnosis of } \mathrm{AKI} \mathrm{I}\left[\mathrm{ml} / \mathrm{min} / \mathrm{m}^{2}\right]\end{array}$ & $0.997(0.994-0.99)$ & 0.01 \\
\hline First calculated MPP & $0.995(0.92-0.99)$ & 0.03 \\
\hline Age [years] & $1.02(0.997-1.05)$ & 0.09 \\
\hline $\begin{array}{l}\text { Cumulative fluid balance on } \\
\text { day of AKI I [ml] }\end{array}$ & $1.00(0.99-1.00)$ & 0.98 \\
\hline $\begin{array}{l}\text { MAP }<65 \mathrm{mmHg} \text { for }>1 \mathrm{~h} \text { in } \\
\text { first } 12 \mathrm{~h} \text { after diagnosis of AKI I }\end{array}$ & $0.97(0.48-1.96)$ & 0.93 \\
\hline
\end{tabular}

Abbreviations: $\mathrm{Cl}$ confidence interval, $D O_{2} l$ oxygen delivery index, MAP mean arterial pressure, MPP mean perfusion pressure, $O R$ odds ratio, SOFA sequential organ failure assessment

${ }^{a}$ controlled for age, oxygen delivery index, arterial lactate concentration, cumulative fluid balance and SOFA score

factor for progression to AKI III (OR 1.08; 95\% CI $1.02-1.14 ; p=0.005)$ after controlling for age, oxygen delivery index, arterial lactate, cumulative fluid balance and SOFA score. In contrast, MAP during the $12 \mathrm{~h}$ period after diagnosis of AKI I was not independently associated with risk of progression $(\mathrm{OR}=0.96,95 \% \mathrm{CI}=0.92-1.00, p=0.079)$. Further analyses to explore whether the effect of CVP differed by MAP showed that the interaction was statistically not significant $(\mathrm{OR}=1.00 ; 95 \%$ CI $0.99-1.01$; $p=0.88)$.

\section{Discussion}

This retrospective single-centre study shows that MPP during the $12 \mathrm{~h}$ period following diagnosis of AKI stage $\mathrm{I}$ is independently associated with risk of progression to AKI III. The association between MPP and progression

Table 3 Subgroup analyses: Adjusted association between MPP and progression to AKI III

\begin{tabular}{lll}
\hline Patient cohort & OR $(95 \% \mathrm{Cl})^{\mathrm{a}}$ & $p$-value \\
\hline No IHD / CCF & $0.98(0.92-1.04)$ & 0.49 \\
IHD / CCF & $0.92(0.86-0.98)$ & 0.019 \\
MAP not $<65 \mathrm{mmHg}$ for $>1 \mathrm{~h}$ & $0.960 .90-1.02)$ & 0.23 \\
MAP $<65 \mathrm{mmHg}$ for $>1 \mathrm{~h}$ & $0.93(0.87-0.98)$ & 0.013 \\
CVP $\leq 15 \mathrm{mmHg}$ & $0.94(0.87-1.01)$ & 0.08 \\
CVP $>15 \mathrm{mmHg}$ & $0.98(0.92-1.04)$ & 0.47 \\
No pre-existing hypertension & $0.93(0.88-0.99)$ & 0.032 \\
Pre-existing hypertension & $0.96(0.90-1.03)$ & 0.259 \\
\hline
\end{tabular}

Abbreviations: AKI acute kidney injury, CCF congestive cardiac failure, IHD ischaemic heart disease, CVP central venous pressure, MAP mean arterial pressure, MPP mean perfusion pressure, $O R$ odds ratio, $\mathrm{Cl}$ confidence interval arepresents the change in odds of progression to AKI III associated with a one unit increase in MPP adjusted for age, oxygen delivery index, arterial lactate concentration, cumulative fluid balance and SOFA score was particularly strong in patients with IHD or CCF, those without pre-existing hypertension and in patients with a MAP $<65 \mathrm{mmHg}$ for $>1 \mathrm{~h}$. CVP was the key component of the MPP with independent impact on risk of progression to AKI III whereas MAP was not independently associated with progression.

The finding that elevated CVP can lead to renal dysfunction was first demonstrated in experimental animal studies $[8,23,24]$. Potential mechanisms include transmission of back pressure to the renal veins, increased pressure along the renal vascular tree leading to compression of tubules and decreased net pressure gradient across the glomerulus, ultimately resulting in decreased glomerular filtration.

In humans, the evidence for an association between CVP and AKI stems predominantly from patients with cardiac disease [15]. A sub-analysis of the ESCAPE (Evaluation Study of Congestive Heart Failure and Pulmonary Artery Catheterization Effectiveness) study in patients with decompensated heart failure revealed that among the haemodynamic parameters measured only right atrial pressure correlated with renal function [11]. A different study in 145 patients with acute decompensated heart failure admitted to the Cleveland Clinic confirmed a direct progressive association between baseline CVP and incidence of AKI: when CVP reached $>16$ or $>24 \mathrm{mmHg}$, the incidence of AKI was 59 or $75 \%$, respectively [12]. Other haemodynamic variables were not independent risk factors for AKI. In cardiac surgery cohorts where systemic venous congestion is a hallmark feature, such as in patients with right valve pathology, AKI is also very prevalent [15]. Williams et al. analysed the data of 1497 patients who underwent coronary artery bypass grafting and had either an ejection fraction $<40 \%$ or an age $>65$ years [16]. They showed that for CVP increments of $5 \mathrm{mmHg}$ above the threshold of $9 \mathrm{mmHg}$, the risk-adjusted odds ratio for AKI was 1.3 (95\% CI $1.01-1.65 ; p=0.045)$. In congestive heart failure, the increased backward pressure appears to propagate in all districts of the venous system, including renal veins.

We found that the relationship between MPP and AKI progression was primarily based on an independent association between CVP and AKI. In fact, more than 150 years ago, Ludwig and colleagues made similar observations [21]. They showed that if pressure in the renal veins was raised by about $10 \mathrm{mmHg}$, urine flow was reduced. They attributed this to the histological observation that an increase of venous pressure was associated with distended venules surrounding the distal ends of the tubules resulting in obliteration of the lumen of the tubules. In 1931, using animal models, Winton and colleagues showed that an increase in venous pressure resulted in greater diminution of intrarenal blood flow than a corresponding change in arterial pressure 
[8]. Our finding that a rise in CVP was independently associated with progression from AKI I to AKI III whereas a fall in MAP in isolation was not an independent risk factor, complements these observations from 100 years ago.

To date, studies have focussed on the link between CVP and risk of AKI. To our best knowledge, our study is the first which analysed patients who had already developed AKI and explored the association between MAP, CVP and risk of progression to severe AKI. Physiologically, our conclusion that a reduced MPP is associated with an increased risk of progression makes sense. The finding that a higher CVP had a greater impact on the effects of progression than a lower MAP is also supported by basic physiology studies in the literature $[8,24]$.

Measuring renal congestion by imaging is challenging at the bedside and requires extensive patient manipulation, which, in the critically ill patient greatly reduces the practical applicability of any given technique [17]. Based on our data, we suggest that a calculated MPP $\leq 59 \mathrm{mmHg}$ in the early phase of AKI I may serve as a surrogate marker of increased risk for progression to AKI stage III. Although we did not study any potential interventions, our data also imply that in cardiac patients with AKI stage I and a MPP $\leq 59 \mathrm{mmHg}$, further fluid loading may not be advisable if this leads to an increase in CVP. Clearly, more studies are necessary to investigate whether MPP could serve as tool to assess the risk of AKI and a guide for potential therapeutic manipulation, including attempts to reduce CVP.

Our analysis has all limitations of a retrospective single centre study with a heterogeneous patient population. We also acknowledge that we calculated MPP but did not perform invasive renal pressure monitoring or imaging techniques for comparison. Second, we only analysed patients in whom haemodynamic monitoring had been performed for clinical reasons. Third, we defined AKI by serum creatinine results obtained during hospitalisation only. We did not use urine output criteria and may have missed cases with AKI stage I. Finally, the study design was non-interventional, and the association between MPP and progression of AKI does not prove a causal relationship. Whether actively increasing MPP by raising MAP or lowering CVP may reduce the risk of progression to AKI III needs to be evaluated in future studies.

\section{Conclusions}

Our study showed that MPP $\leq 59 \mathrm{mmHg}$ is independently associated with progression of AKI in ICU and this association is particularly strong in patients with IHD/ $\mathrm{CCF}$, those without pre-existing hypertension and in patients with MAP $<65 \mathrm{mmHg}$ for $>1 \mathrm{~h}$. A raised CVP had a greater impact on AKI progression than MAP.

\section{Abbreviations}

AKI: Acute kidney injury; AKIN: Acute kidney injury network; APACHE: Acute physiology and chronic health evaluation; CCF: Congestive cardiac failure; $\mathrm{Cl}$ : Confidence interval; CKD: Chronic kidney disease; CLD: Chronic liver disease; COPD: Chronic obstructive pulmonary disease; CVP: Central venous pressure; $\mathrm{DO}_{2}$ I: Indexed oxygen delivery; ESCAPE: Evaluation study of congestive heart failure and pulmonary artery catheterisation effectiveness; ESRD: End stage renal disease; ICU: Intensive care unit; IHD: Ischaemic heart disease; IQR: Interquartile range; MAP: Mean arterial pressure; MPP: Mean perfusion pressure; OR: Odds ratio; SD: Standard deviation; SOFA: Sequential organ failure assessment

\section{Acknowledgement}

We wish to thank Dr. M Raimundo, Dr. Y Syed and Dr. JR Martin for helping with the data collection and Dr. R Fisher for reviewing the paper and providing helpful suggestions.

\section{Funding}

None.

\section{Availability of data and materials}

The datasets generated and/or analysed during the current study are not publicly available but are available from the corresponding author on reasonable request.

\section{Authors' contributions}

MO conceived and led the study, interpreted the data, and revised the manuscript critically for important intellectual content. AH drafted and revised the manuscript and interpreted the data. SC analysed and interpreted the patient data and participated in critical review of the final manuscript. All authors read and approved the final manuscript.

\section{Competing interests}

The authors declare that they have no competing interests.

Consent for publication

Not applicable.

\section{Ethics approval and consent to participate}

This study had institutional approval. The South East London Research Ethics Committee, London (UK), confirmed that there was no need for individual informed consent because this was a retrospective analysis of data collected prospectively for routine care with no breach of privacy or anonymity (UK National Research Ethics Service).

\section{Publisher's Note}

Springer Nature remains neutral with regard to jurisdictional claims in published maps and institutional affiliations.

\section{Author details}

'Department of Critical Care, King's College London, Guy's \& St Thomas' NHS Foundation Trust, Westminster Bridge Road SE1 7 EH, London, UK. 2Department of Critical Care, Guy's \& St Thomas' NHS Foundation Trust, Westminster Bridge Road, London SE1 7EH, UK. ${ }^{3}$ Division of Health and Social Care Research, King's College London, London, UK.

Received: 3 February 2017 Accepted: 22 April 2017

Published online: 03 May 2017

References

1. Hoste E, Bagshaw S, Bellomo R, Cely CM, Coman R, Cruz DN, et al. Epidemiology of acute kidney injury in critically ill patients: the multinational AKI-EPI study. Intensive Care Med. 2015;41(8):1411-23.

2. Ostermann M, Chang RW. Riyadh ICU program users group. Correlation between the AKI classification and outcome. Crit Care. 2008;12:144.

3. Lewington A, Cerdá J, Mehta R. Raising awareness of acute kidney injury: a global perspective of a silent killer. Kidney Int. 2013;84(3):457-67.

4. Mehta R, Cerdá J, Burdmann E, Tonelli M, Garcia-Carcia G, Jha V, et al. International Society of Nephrology's 0by25 initiative for acute kidney injury (zero preventable deaths by 2025): a human rights case for nephrology. Lancet. 2015;385(9987):2616-43. 
5. Chawla LS, Eggers PW, Star RA, Kimmel PL. Acute kidney injury and chronic kidney disease as interconnected syndromes. N Engl J Med. 2014;371:58-66.

6. Loutzenhiser R, Griffin K, Williamson G, Bidani A. Renal autoregulation: new perspectives regarding the protective and regulatory roles of the underlying mechanisms. Am J Physiol Regul Integr Comp Physiol. 2006;290(5):R1153-67.

7. Firth J, Raine A, Ledingham J. Raised venous pressure: a direct cause of renal sodium retention in oedema? Lancet. 1988; (8593):1033-5.

8. Winton $F$. The influence of venous pressure on the isolated mammalian kidney. J Physiol. 1931;72(1):49-61.

9. Burnett J, Knox F. Renal interstitial pressure and sodium excretion during renal vein constriction. Am J Phys. 1980;238(4):279-82.

10. Maxwell M, Breed E, Schwartz I. Renal venous pressure in chronic congestive heart failure. J Clin Invest. 1950;29(3):342-8.

11. Nohria A, Hasselblad V, Stebbins A, Pauly DF, Fonarow GC, Shah M, et al. Cardio-renal interactions: insights from the ESCAPE trial. J Am College Cardiol. 2008:51(13):1268-74.

12. Mullens W, Abrahams Z, Francis GS, Sokos G, Taylor DO, Starling RC, et al. Importance of venous congestion for worsening of renal function in advanced decompensated heart failure. J Am College Cardiol. 2009;53(7):589-96.

13. Damman K, van Deursen V, Navis G, Voors AA, van Veldhuisen DJ, Hillege $\mathrm{HL}$. Increased central venous pressure is associated with impaired renal function and mortality in a broad spectrum of patients with cardiovascular disease. J Am College Cardiol. 2009;53(7):582-8.

14. Damman K, Navis G, Smilde TD, Voors AA, van der Bij W, Van Veldhuisen DJ, Hillege HL. Decreased cardiac output, venous congestion and the association with renal impairment in patients with cardiac dysfunction. Eur J Heart Fail. 2007;9(9):872-8.

15. Gambardella I, Gaudino M, Ronco C, Lau C, Ivascu N, Girardi LN. Congestive kidney failure in cardiac surgery: the relationship between central venous pressure and acute kidney injury. Interact Cardiovasc Thorac Surg. 2016;23: $800-5$.

16. Williams JB, Peterson ED, Wojdyla D, Harskamp R, Southerland KW, Ferguson $T B$, et al. Central venous pressure after coronary artery bypass surgery: does it predict postoperative mortality or renal failure? J Crit Care. 2014;29:1006-10.

17. Schneider A, Goodwin M, Bellomo R. Measurement of kidney perfusion in critically ill patients. Crit Care. 2013;17(2):220.

18. Panwar R, Lanyon N, Davies AR, Bailey M, Pilcher D, Bellomo R. Mean perfusion pressure deficit during the initial management of shock - an observational cohort study. J Crit Care. 2013;28:816-24.

19. Wong BT, Chan MJ, Glassford NJ, Martensson J, Bion V, Chai SY, et al. Mean arterial pressure and mean perfusion pressure deficit in septic acute kidney injury. J Crit Care. 2015;30:975-81.

20. Raimundo M, Crichton S, Syed Y, Martin JR, Beale R, Treacher D, Ostermann M. Low systemic oxygen delivery and BP and risk of progression of early acute kidney injury. Clin J Am Soc Nephrol. 2015;10(8):1340-9.

21. Raimundo M, Crichton S, Martin JR, Syed Y, Varrier M, Wyncoll D, Ostermann M. Increased fluid administration after early acute kidney injury is associated with less renal recovery. Shock. 2015;44(5):431-7.

22. Mehta R, Kellum J, Shah S, Molitoris BA, Ronco C, Warnock DG, Levin A. Acute kidney injury network. Acute kidney injury network: report of an initiative to improve outcomes in acute kidney injury. Crit Care. 2007;11(2):R31.

23. Burnett J, Haas J, Knox F. Segmental analysis of sodium reabsorption during renal vein constriction. Am J Phys. 1982;243(1):19-22.

24. Ludwig C. Lehrbuch der Physiology. 2nd edition. 1861. p. 373.

\section{Submit your next manuscript to BioMed Central and we will help you at every step:}

- We accept pre-submission inquiries

- Our selector tool helps you to find the most relevant journal

- We provide round the clock customer support

- Convenient online submission

- Thorough peer review

- Inclusion in PubMed and all major indexing services

- Maximum visibility for your research

Submit your manuscript at www.biomedcentral.com/submit

) Biomed Central 